\title{
Discontinuation/Interruption of Warfarin Therapy in Patients with Nonvalvular Atrial Fibrillation
}

\author{
Christina A. Spivey, PhD; Yanru Qiao, MS; Xianchen Liu, MD, PhD; Jack Mardekian, PhD; \\ Robert B. Parker, PharmD; Hemant Phatak, PhD; Abigail B. Claflin, MPH; Sumesh Kachroo, PhD; \\ Younos Abdulsattar, PharmD, BCPS; Anwesa Chakrabarti, PharmD Candidate; and Junling Wang, PhD
}

\section{ABSTRACT}

BACKGROUND: Use of warfarin is standard of care for stroke prevention in patients with atrial fibrillation (AF). However, AF patients experience high rates of warfarin discontinuation/interruption, resulting in increased health risks and health care costs. As such, it is important to study the rates and predictors of warfarin discontinuation/interruption in this population.

OBJECTIVES: To determine (a) rates of warfarin discontinuation and interruption and (b) demographic, clinical, and health care-related factors associated with discontinuation and interruption in patients with nonvalvular $\mathrm{AF}$ (NVAF) in the usual clinical practice settings in the United States.

METHODS: This retrospective cohort study used the MarketScan Database and included patients (aged $\geq 18$ years) with NVAF who were initiated on warfarin. The study period was January 1,2008 , to June 30,2012 . To be included, patients were required to have at least 2 claims with $\mathrm{AF}$ diagnosis separated by $\geq 30$ days and $\leq 12$ months and at least 1 outpatient claim. Warfarin initiation had to occur within 30 days of the AF diagnosis. Patients also had to have continuous enrollment in prescription drug plans from 6 months prior to warfarin use to at least 12 months after warfarin initiation. Patients were followed for 1 year after warfarin initiation. Persistence was defined as warfarin therapy without a gap $\geq 45$ days between the end date of the former prescription and the start date of the current prescription or with international normalized ratio (INR) monitoring at least every 42 days. Interruption was defined as a gap in warfarin therapy $\geq \mathbf{4 5}$ days and $\leq 90$ days between the end date of the former prescription and the start date of the current prescription and without INR monitoring at least every 42 days. Discontinuation was defined as $>90$ days without warfarin therapy between the end date of the former prescription and the start date of the current prescription and without INR monitoring at least every $\mathbf{4 2}$ days. Chi-square tests were used to analyze categorical variables, and independent samples t-tests were used for continuous variables. Cox proportional hazards regression model was performed to determine factors associated with warfarin discontinuation/interruption, including demographic (e.g., age, gender); clinical (e.g., comorbidities, CHADS $_{2}$ score); and health care-related (e.g., hospitalizations or emergency room visits) characteristics. Sensitivity analyses were conducted by varying prescription gaps by 7,14 , and 30 days.

RESULTS: A total of 58,593 patients with NVAF were included. The mean age was approximately 71 years $(S D=12.00)$ and mean CHADS $_{2}$ score was $1.66(S D=1.23)$. The majority of patients were male $(60 \%)$. During 12 months after warfarin initiation, $45 \%$ of patients were persistent with warfarin; $12 \%$ had interruption without discontinuation; and $43 \%$ had discontinuation. The risk of warfarin interruption or discontinuation was significantly greater in patients who were younger than 65 years $(H R=1.22$; $95 \% \mathrm{Cl}=1.19-1.25)$, lived in the West ( $\mathrm{HR}=1.07 ; 95 \% \mathrm{Cl}=1.03-1.11)$, had history of anemia $(\mathrm{HR}=1.10 ; 95 \% \mathrm{Cl}=1.06-1.14)$, had history of bleeding ( $\mathrm{HR}=1.10 ; 95 \% \mathrm{Cl}=1.06-1.14)$, or had history of hospitalization or emergency room visits $(\mathrm{HR}=1.11 ; 95 \% \mathrm{Cl}=1.08-1.13)$. The significant factors associated with interruption and discontinuation were similar. In the sensitivity analyses, the significant factors associated with discontinuation/ interruption were similar across different prescription gaps.

CONCLUSIONS: In the U.S. clinical practice setting, more than $50 \%$ of NVAF patients discontinued or interrupted warfarin within 1 year after initiation. Aged $<65$ years, history of anemia, and history of hospitalization/emergency room visits were associated with increased risk of discontinuation/interruption. Given the high prevalence of warfarin discontinuation/interruption, health care providers should take a more active role in understanding and addressing the reasons behind patient discontinuation/interruption.

\section{J Manag Care Spec Pharm. 2015;21(7):596-606}

Copyright $\odot 2015$, Academy of Managed Care Pharmacy. All rights reserved.

\section{What is already known about this subject}

Warfarin treatment is associated with significant reductions in the risk of thromboembolic events in patients with atrial fibrillation. A high percentage of patients discontinue warfarin within the first year of use. Warfarin discontinuation is associated with stroke risk.

Factors related to warfarin discontinuation/interruption include bleeding episodes, surgery, inconvenience, return to stable cardiac rhythm, noncompliance, poor anticoagulation control, history of dysrhythmias, lower risk of stroke, history of hospitalization and emergency room visits, and patient age.

\section{What this study adds}

This study used a national database and differentiated between warfarin interruption and discontinuation when studying warfarin utilization patterns.

More than half of the study participants interrupted or discontinued warfarin therapy during the first year of use: $11.77 \%$ interrupted warfarin therapy without warfarin discontinuation, and $43.45 \%$ of patients discontinued warfarin therapy with or without warfarin interruption

Individuals who were younger than 65 years, had anemia, had bleeding episodes, or were hospitalized or had emergency room visits were at significantly higher risk of warfarin discontinuation/interruption. 
A trial fibrillation $(\mathrm{AF})$ is one of the most commonly encountered cardiac arrhythmias. ${ }^{1-3}$ Prevalence of AF increases with age, and as a greater subset of the American population ages, the burden of this disease will also increase. ${ }^{4}$ The number of adult individuals with $\mathrm{AF}$ in the United States is expected to increase from 5.2 million in 2010 to 12.1 million by $2030 .{ }^{5}$ The steadily increasing population with $\mathrm{AF}$ is a concern due to the health risks associated with AF. $\mathrm{AF}$ is considered a significant risk factor for thromboembolic events and stroke. ${ }^{6}$ More specifically, patients with nonvalvular $\mathrm{AF}$ (NVAF) are 2 to 7 times more likely to experience ischemic stroke than patients without $\mathrm{AF}^{1,7}$

Administration of anticoagulants such as warfarin is associated with notable reductions in the risk of thromboembolic events in patients with $\mathrm{AF}$, as recommended by practice guidelines such as those by the American College of Cardiology, American Heart Association, and European Society of Cardiology. ${ }^{1-4,8-11}$ Warfarin decreases the risk of stroke by $64 \%$ to $86 \%$ compared with placebo. ${ }^{12-16}$ Warfarin has also been associated with decreased total health care costs among patients with $\mathrm{AF}$ in comparison with patients who were not taking warfarin. ${ }^{17}$ However, despite its many benefits, warfarin is associated with adverse events, particularly bleeding and its resulting costs, which likely play a substantive role in warfarin nonpersistence (i.e., discontinuation or interruption). ${ }^{10,12,18,19}$ Other problems with warfarin therapy include the need to frequently monitor the degree of anticoagulation, many drugdrug interactions, drug-food interactions, drug-disease interactions, and genetic polymorphisms affecting warfarin disposition and response.

Generally, studies have found that a high percentage of patients, ranging from approximately $25 \%$ to $65 \%$, discontinue warfarin within the first year of use. ${ }^{18,20-25}$ For example, of more than 4,000 AF patients in Fang et al.'s (2010) Anticoagulation and Risk Factors in Atrial Fibrillation Study, approximately $26 \%$ discontinued warfarin within 1 year of initiation. ${ }^{20}$ Patel et al. (2013) found that within 90 days of initiation, 37\% of longterm care residents with AF discontinued warfarin; by 1 year postwarfarin initiation, the discontinuation rate increased to $65 \% .{ }^{25} \mathrm{~A}$ number of factors contribute to warfarin discontinuation among AF patients. A study by Suh et al. (2013) found that recent bleeding increased the probability for warfarin discontinuation by $35 \%$, while Fang et al. found that hospitalization from a hemorrhagic event led to warfarin discontinuation 65\% of the time..$^{18,20}$ Other factors related to warfarin discontinuation/interruption include recent bleeding episodes; surgery; frailty/risk of falls (particularly in older patients); return to stable cardiac rhythm; noncompliance; poor anticoagulation control; history of dysrhythmias; lower risk of stroke as indicated by $\mathrm{CHADS}_{2}$ score $\mathrm{CHADS}_{2}$ is a clinical rule that estimates the stroke risk in patients with $\mathrm{AF}$ by factoring in congestive heart failure, hypertension, aged $\geq 75$ years, diabetes, and prior stroke/transient ischemic attack [TIA]); history of hospitalization and emergency room visits; and patient age. ${ }^{18,20,22-24,26-28}$

There are serious clinical consequences to warfarin discontinuation/interruption. As observed by Ewen et al. (2012), patients who experience multiple warfarin interruptions have more than twice the risk for stroke compared with patients with no interruptions. ${ }^{21}$ Studies have also shown significant health care costs related to warfarin discontinuation/interruption..$^{27,29}$ Due to the prevalence of discontinuation/interruption in warfarin-treated AF patients and the associated negative health outcomes and increased health care costs, it is important to study the patterns and predictors of warfarin discontinuation and interruption. Increased understanding of discontinuation and interruption may assist health care professionals and managed care organizations in their attempts to improve warfarin therapy use in AF patients. Because previous studies used small sample sizes, the purpose of the current study was to assess warfarin persistence, discontinuation, and interruption in a broad U.S. patient population. The specific objectives were to determine (a) rates of discontinuation and interruption of warfarin therapy and (b) demographic, clinical, and health care-related factors associated with discontinuation and interruption.

\section{Methods}

\section{Study Design}

This retrospective cohort study used the Truven MarketScan Commercial Claims and Encounters and Medicare Supplemental and Coordination of Benefits databases (January 1, 2008, to June 30, 2012). MarketScan is a de-identified, nationwide medical claims database licensed by Truven Health Analytics. It is compliant with the Health Insurance Portability and Accountability Act and includes enrollment data and insurance claims for inpatient, outpatient, emergency room, pharmacy, and behavioral health care. A unique enrollee identifier is assigned to each individual, which enables cross-linkage of all health care information in the database.

The study population included patients (aged $\geq 18$ years) with NVAF who were initiated on warfarin therapy. The inclusion and exclusion criteria for this study are described in Figure 1. To be included, patients with an NVAF diagnosis were required to have at least 2 claims with primary or secondary AF diagnosis, identified by an International Classification of Diseases, Ninth Revision, Clinical Modification (ICD-9-CM) code of 427.31 , separated by $\geq 30$ days and $\leq 12$ months and at least 1 outpatient claim with $\mathrm{AF}$ diagnosis. ${ }^{29}$ Warfarin prescription was determined by either generic or brand name (generic name: warfarin sodium and warfarin potassium; brand name: Coumadin, Jantoven, Marevan, Lawarin, Waran, or Athrombin-K and Warfant) from July 1, 2008, to June 30, 2011. Patients had no record of warfarin use or international normalized ratio (INR) monitoring (defined using Current 


\section{FIGURE 1 Flowchart of Sample Selection}

All commercial population with pharmacy claims in MarketScan database from January 1, 2008, to June 30, 2012 $\mathrm{N}=1,443,282$

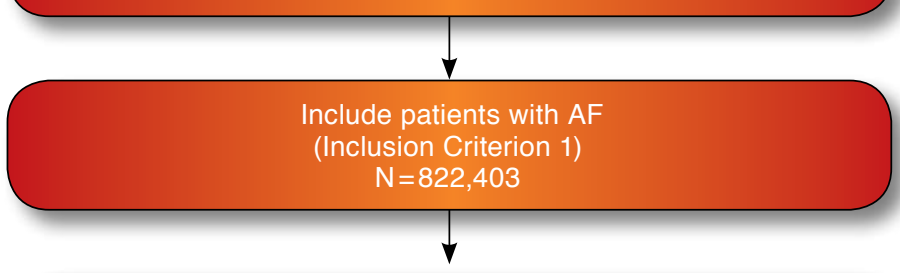

Include patients who filled at least 1 prescription for warfarin between July 1,2008, and June 30, 2011 (Inclusion Criterion 2) $\mathrm{N}=490,517$

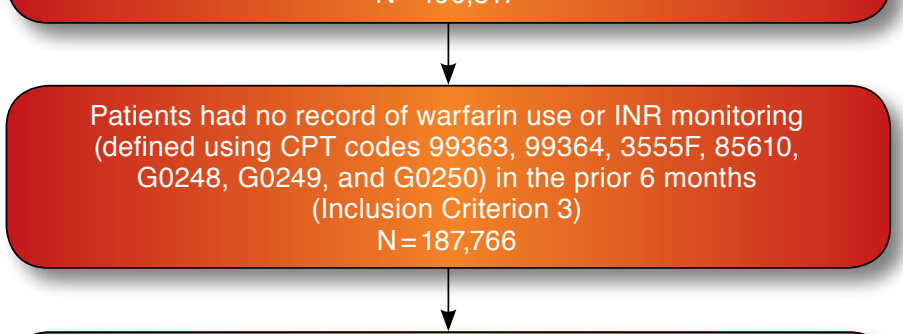

The AF diagnosis had to occur within 30 days of warfarin initiation

(Inclusion Criterion 4) $\mathrm{N}=131,035$

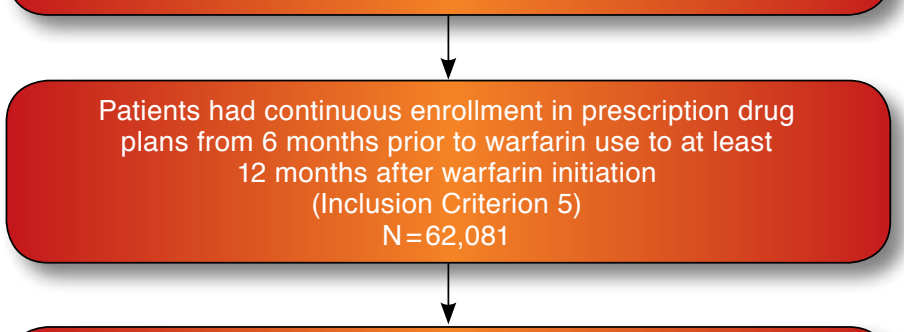

Patients were aged 18 years or older as of index date

(Inclusion Criterion 6) $\mathrm{N}=62,077$

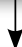

Exclude patients with mitral or aortic valvular repair

or replacement, transient perioperative AF,

or hyperthyroidism

(Exclusion Criterion)

$\mathrm{N}=58,593$

$\overline{A F=\text { atrial fibrillation; } C P T=\text { Current Procedural Terminology; INR=international }}$ normalized ratio.

Procedural Terminology codes 99363, 99364, 3555F, 85610, G0248, G0249, and G0250) in the prior 6 months. This was done to maximize the probability that patients were new warfarin users. ${ }^{12,30,31}$ Warfarin initiation had to occur within 30 days of the AF diagnosis to cover delayed entry of diagnosis codes and maximize the probability that patients were newly diagnosed with AF and were receiving warfarin for stroke prevention. ${ }^{12}$ The index date was defined as the day when the first warfarin prescription that met the aforementioned criteria was filled. Patients also had to have continuous enrollment in prescription drug plans from 6 months prior to warfarin use to at least 12 months after warfarin initiation. This was required so that patients could be observed for warfarin persistency patterns for 12 months. ${ }^{21}$ Patients with mitral or aortic valvular repair or replacement (ICD-9-CM codes 394.0, 394.2, 396.0, $396.1,396.8, \mathrm{v} 43.3, \mathrm{v} 42.2,35.10-35.14$, and 35.20-35.28); transient perioperative AF (ICD-9-CM codes 36.10-36.19, 37.10-37.12, 37.31-37.33, 37.40, 35.00-35.04, 35.31-35.39, 35.4135.42 , 35.50-35.56, 35.60-35.63, and 35.70-35.73); or hyperthyroidism (ICD-9-CM codes 242.0-242.9) were excluded to eliminate potential confounding effects in the analysis. Patient enrollment records were used to determine whether patients met the inclusion criteria for age and continuous enrollment.

\section{Measures of Persistence, Interruption, and Discontinuation}

Based on the MarketScan database, all medications that patients filled, including warfarin, were obtained from outpatient pharmaceutical claims. The names of medications that patients filled were identified by linking the outpatient pharmaceutical claims to the RED BOOK using the National Drug Code numbers provided as part of MarketScan. ${ }^{32}$ Patients were followed for 365 days after their warfarin initiation dates for persistence, interruption, and discontinuation status. Persistence was defined as warfarin therapy without a gap $\geq 45$ days between the end date of the former prescription and the start date of the current prescription or with INR monitoring at least every 42 days. ${ }^{20,21,33}$ Interruption was defined as a gap in warfarin therapy $\geq 45$ days and $\leq 90$ days between the end date of the former prescription and the start date of the current prescription and without INR monitoring at least every 42 days. ${ }^{20,21,33}$ Discontinuation was defined as $>90$ days without warfarin therapy between the end date of the former prescription and the start date of the current prescription and without INR monitoring at least every 42 days. ${ }^{18,20}$ Patients were classified into 4 warfarin persistency categories: (1) persistent, (2) interruption without discontinuation, (3) discontinuation with interruption, and (4) discontinuation without interruption. ${ }^{18,21,30}$

\section{Independent Variables}

The independent demographic, clinical, and health care-related factors included in the study were as follows: age; gender; U.S. census regions (Northeast, North Central, South, West, and Other); and types of health care plans (comprehensive plans, preferred provider organizations [PPO], health maintenance organizations [HMO], and other plans), These variables were determined on the index date. Meanwhile, patient comorbidities 


\begin{tabular}{|c|c|c|c|c|c|c|c|c|c|}
\hline \multirow{2}{*}{\multicolumn{2}{|c|}{ Patient Characteristics }} & \multicolumn{2}{|c|}{$\begin{array}{l}\text { All Warfarin } \\
\text { Patients }\end{array}$} & \multicolumn{2}{|c|}{$\begin{array}{l}\text { Persistent } \\
\text { Patients }\end{array}$} & \multicolumn{2}{|c|}{$\begin{array}{l}\text { Patients with } \\
\text { Interruption }\end{array}$} & \multicolumn{2}{|c|}{$\begin{array}{c}\text { Patients with } \\
\text { Discontinuation }\end{array}$} \\
\hline & & $\mathbf{n}$ & $\%$ & $\mathbf{n}$ & $\%$ & $\mathbf{n}$ & $\%$ & $\mathbf{n}$ & $\%$ \\
\hline \multicolumn{2}{|c|}{ Total $(\mathrm{n})^{\mathrm{a}, \mathrm{b}}$} & 58,593 & 100.0 & 26,241 & 44.8 & 8,020 & 13.7 & 24,332 & 41.5 \\
\hline \multicolumn{2}{|c|}{ Age $(\text { mean } \pm \text { SD) })^{a, b}$} & \multicolumn{2}{|c|}{$70.89 \pm 12.00$} & \multicolumn{2}{|c|}{$72.06 \pm 11.27$} & \multicolumn{2}{|c|}{$72.36 \pm 11.54$} & \multicolumn{2}{|c|}{$69.13 \pm 12.68$} \\
\hline \multirow[t]{2}{*}{ Age } & $<65$ & 18,720 & 32.0 & 7,363 & 28.1 & 2,085 & 26.0 & 9,272 & 38.1 \\
\hline & $\geq 65$ & 39,873 & 68.0 & 17,878 & 71.9 & 5,935 & 74.0 & 15,060 & 61.9 \\
\hline \multirow[t]{2}{*}{ Gender ${ }^{b}$} & Male & 34,917 & 59.6 & 15,237 & 58.1 & 4,628 & 57.7 & 15,052 & 61.9 \\
\hline & Female & 23,676 & 40.4 & 11,004 & 41.9 & 3,392 & 42.3 & 9,280 & 38.1 \\
\hline \multirow[t]{5}{*}{ Region $^{\mathrm{a}, \mathrm{b}}$} & Northeast & 9,096 & 15.5 & 4,107 & 15.7 & 1,242 & 15.5 & 3,747 & 15.4 \\
\hline & North central & 19,087 & 32.6 & 8,828 & 33.6 & 2,659 & 33.2 & 7,600 & 31.2 \\
\hline & South & 19,037 & 32.5 & 8,386 & 32.0 & 2,480 & 30.9 & 8,171 & 33.6 \\
\hline & West & 11,137 & 19.0 & 4,806 & 18.3 & 1,618 & 20.2 & 4,713 & 19.4 \\
\hline & Other & 236 & 0.4 & 114 & 0.4 & 21 & 0.3 & 101 & 0.4 \\
\hline \multirow[t]{4}{*}{ Plan type $^{\mathrm{a}, \mathrm{b}}$} & Comprehensive & 21,177 & 36.1 & 9,947 & 38.8 & 3,164 & 40.4 & 8,066 & 33.9 \\
\hline & $\mathrm{PPO}$ & 24,041 & 41.0 & 10,452 & 40.8 & 3,067 & 39.1 & 10,522 & 44.2 \\
\hline & $\mathrm{HMO}$ & 7,281 & 12.4 & 3,215 & 12.5 & 1,068 & 13.6 & 2,998 & 12.6 \\
\hline & Other & 4,776 & 8.2 & 2,031 & 7.9 & 538 & 6.9 & 2,207 & 9.3 \\
\hline \multicolumn{2}{|c|}{$\mathrm{CHADS}_{2}(\text { mean } \pm \mathrm{SD})^{\mathrm{a}, \mathrm{b}}$} & \multicolumn{2}{|c|}{$1.66 \pm 1.23$} & \multicolumn{2}{|c|}{$1.77 \pm 1.24$} & \multicolumn{2}{|c|}{$1.73 \pm 1.21$} & \multicolumn{2}{|c|}{$1.50 \pm 1.21$} \\
\hline \multirow{5}{*}{$\mathrm{CHADS}_{2}$ score $^{\mathrm{b}}$} & 0 & 10,424 & 17.8 & 3,856 & 14.7 & 1,185 & 14.8 & 5,383 & 22.1 \\
\hline & 1 & 18,436 & 31.5 & 7,964 & 30.4 & 2,492 & 31.1 & 7,980 & 32.8 \\
\hline & 2 & 16,909 & 28.9 & 8,007 & 30.5 & 2,498 & 31.2 & 6,404 & 26.3 \\
\hline & 3 & 8,119 & 13.9 & 3,936 & 15.0 & 1,178 & 14.7 & 3,005 & 12.4 \\
\hline & $4-6$ & 4,705 & 8.0 & 2,478 & 9.4 & 667 & 8.3 & 1,560 & 6.4 \\
\hline \multicolumn{2}{|c|}{ History of congestive heart failure ${ }^{a, b}$} & 14,015 & 23.9 & 6,467 & 24.6 & 2,066 & 25.8 & 5,482 & 22.5 \\
\hline \multicolumn{2}{|c|}{ History of hypertensiona,b } & 31,722 & 54.1 & 14,734 & 56.2 & 4,242 & 52.9 & 12,746 & 52.4 \\
\hline \multicolumn{2}{|c|}{ History of diabetes mellitus ${ }^{\mathrm{b}}$} & 13,794 & 23.5 & 6,525 & 24.9 & 1,982 & 24.7 & 5,287 & 21.7 \\
\hline \multicolumn{2}{|c|}{ History of stroke or TIA } & 5,744 & 9.8 & 3,127 & 11.9 & 812 & 10.1 & 1,805 & 7.4 \\
\hline \multicolumn{2}{|c|}{ History of anemia ${ }^{b}$} & 8,839 & 15.1 & 3,730 & 14.2 & 1,178 & 14.7 & 3,931 & 16.2 \\
\hline History of bleedi & & 7,085 & 12.1 & 2,948 & 11.2 & 925 & 11.5 & 3,212 & 13.2 \\
\hline$\overline{\mathrm{CCI}(\text { mean } \pm \mathrm{SD})}$ & & & & & & & & & \\
\hline & 0 & 19,501 & 33.3 & 8,109 & 30.9 & 2,468 & 30.8 & 8,924 & 36.7 \\
\hline & 1 & 14,261 & 24.3 & 6,643 & 25.3 & 2,003 & 25.0 & 5,615 & 23.1 \\
\hline & $2-3$ & 15,423 & 26.3 & 7,032 & 26.8 & 2,228 & 27.8 & 6,163 & 25.3 \\
\hline & $4-6$ & 7,698 & 13.1 & 3,674 & 14.0 & 1,089 & 13.6 & 2,935 & 12.1 \\
\hline & $>6$ & 1,710 & 2.9 & 783 & 3.0 & 232 & 2.9 & 695 & 2.9 \\
\hline $\begin{array}{l}\text { History of hospit } \\
\text { emergency visits }\end{array}$ & zation or & 38,586 & 61.2 & 15,916 & 60.7 & 4,827 & 60.2 & 15,113 & 62.1 \\
\hline $\begin{array}{l}\text { a } P<0.05 \text { for the } d \\
b P<0.05 \text { for the } d \\
C C I=\text { Charlson } C c \\
\text { attack. }\end{array}$ & $\begin{array}{l}\text { rence between persi } \\
\text { rence between persi } \\
\text { orbidity Index; HMC }\end{array}$ & $\begin{array}{l}\text { patients } \\
\text { patients }\end{array}$ & $\begin{array}{l}\text { tients } w \\
\text { tients } w \\
\text { ce organ }\end{array}$ & $\begin{array}{l}\text { arin inte } \\
\text { arin disc } \\
P P O=p\end{array}$ & $\begin{array}{l}\text { on. } \\
\text { rovide }\end{array}$ & & & & \\
\hline
\end{tabular}

(congestive heart failure, hypertension, diabetes mellitus, stroke or TIA, and anemia); prior bleeding (gastrointestinal bleeding, intracranial hemorrhage, and other hemorrhage and related procedures based on corresponding ICD-9-CM diagnosis/ procedure codes); $\mathrm{CHADS}_{2}$ score; Charlson Comorbidity Index; and hospitalizations/emergency room visits were also included and determined for the 6-month pre-index period. ${ }^{12,18,30,34}$ The Charlson Comorbidity Index is a measure of health status representing the number of comorbid conditions that a patient has among a total of 22 conditions. ${ }^{35}$ Patients' medical conditions were obtained from outpatient and inpatient claims.

\section{Statistical Analysis}

The rates of discontinuation and interruption in the first year after warfarin initiation were computed. Differences in the distribution of warfarin persistency categories between patients with different demographic (e.g., age and gender); clinical (e.g., comorbidities and $\mathrm{CHADS}_{2}$ score); and health care-related (e.g., hospitalizations or emergency room visits) characteristics were compared. Chi-square tests were used for categorical variables, and independent samples t-tests were used for continuous variables. To identify demographic, clinical, and health care-related 


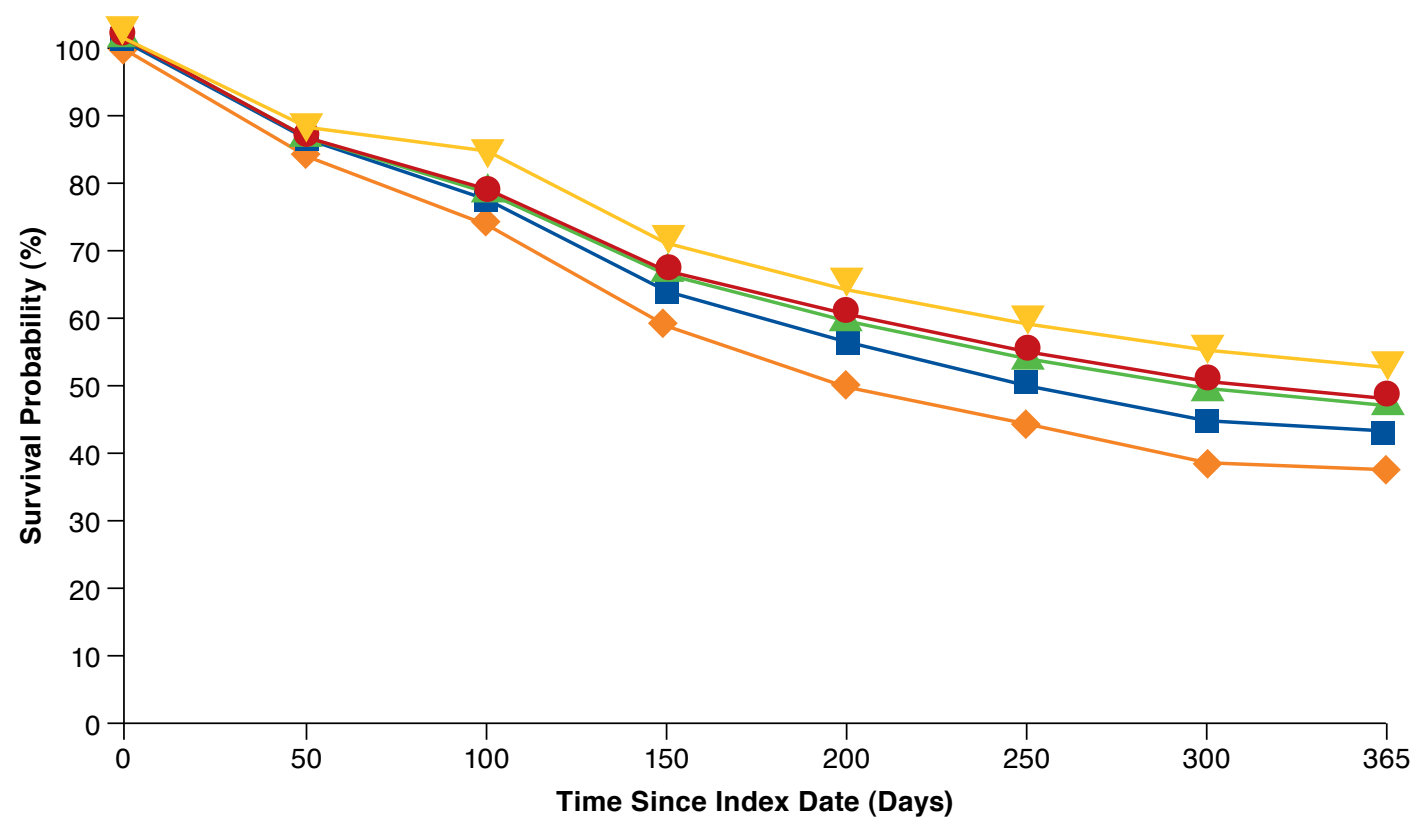

factors associated with warfarin therapy status, patients with warfarin interruption or discontinuation were combined into a discontined/interrupted group to strengthen study power in the main analysis. The time to first warfarin discontinuation/ interruption was depicted using the Kaplan-Meier method, and Kaplan-Meier curves were compared using log-rank test..$^{24,30}$

A Cox proportional hazards regression model was performed to examine demographic, clinical, and health carerelated factors associated with warfarin discontinuation/interruption. The proportionality assumption of the Cox regression model was tested by graphing Kaplan-Meier curves for categorical variables and testing the significance of the interactions between study variables and warfarin persistence time. The Kaplan-Meier curves were reasonably "parallel" across categories of study variables over time. Study findings based on the models including the interaction terms were similar to those without the interaction terms. Therefore, the final findings reported in this study were based on models without the interaction terms for ease of interpretation. Model building in this study was mainly based on relevant literature in addition to a stepwise method with backward elimination (with $P<0.20$ ). To differentiate between factors associated with interruption and discontinuation, patients with warfarin interruption and discontinuation were compared separately with persistent patients. Sensitivity analyses were conducted to assess the robustness of the results by varying the prescription gaps by 7 , 14 , and 30 days in the analyses. ${ }^{25}$ All analyses were conducted using SAS 9.3 (SAS Institute Inc., Cary, NC), and the statistical significance level was set a priori at 0.05 . Institutional review board approval was obtained from the University of Tennessee Health Science Center.

\section{Results}

The patient cohort comprised 58,593 patients who met all inclusion and exclusion criteria (Figure 1). The baseline patient characteristics are summarized in Table 1. Mean age was 70.9 years $(\mathrm{SD}=12.0)$, mean $\mathrm{CHADS}_{2}$ score was $1.66(\mathrm{SD}=1.23)$, and mean Charlson Comorbidity Index was $1.73(\mathrm{SD}=1.93)$.

Within a 12-month follow-up period, 26,241 (44.79\%) patients were persistent with warfarin therapy; 6,895 (11.77\%) had interruption without discontinuation; 23,576 (40.24\%) had discontinuation without interruption; and 1,881 (3.21\%) had discontinuation with interruption. Considering the first episode of interruption or discontinuation only, 26,241 (44.79\%) patients were persistent; 8,020 (13.69\%) interrupted warfarin; and 24,332 (41.53\%) discontinued warfarin. Persistent patients had significantly higher $\mathrm{CHADS}_{2}$ scores compared with patients who interrupted or discontinued warfarin $(P<0.05)$. A significantly greater number of persistent patients had hyper- 
TABLE 2 Demographic, Clinical, and Health Care-Related Factors Associated with Interruption or Discontinuation of Warfarin Based on Multivariate Cox Proportional Hazards Model ${ }^{a}$

\begin{tabular}{|c|c|c|c|c|c|}
\hline Variables & Groups & Estimate & $P$ Value & Hazard Ratio & $\begin{array}{c}95 \% \text { CI for } \\
\text { Hazard Ratio }\end{array}$ \\
\hline \multirow[t]{2}{*}{ Age } & $\geq 65$ & - & - & - & - \\
\hline & $<65$ & 0.20 & $<0.001$ & 1.22 & $1.19-1.25$ \\
\hline \multirow[t]{2}{*}{ Gender } & Male & - & - & - & - \\
\hline & Female & -0.04 & 0.001 & 0.96 & $0.94-0.98$ \\
\hline \multirow[t]{5}{*}{ U.S. census region } & Northeast & - & - & - & - \\
\hline & North central & -0.04 & 0.035 & 0.96 & $0.93-0.99$ \\
\hline & South & 0.016 & 0.357 & 1.02 & $0.98-1.05$ \\
\hline & West & 0.06 & 0.001 & 1.07 & $1.03-1.11$ \\
\hline & Other region & -0.07 & 0.425 & 0.93 & $0.78-1.11$ \\
\hline \multirow[t]{4}{*}{ Health care plan } & Comprehensive & - & - & - & - \\
\hline & $\mathrm{PPO}$ & 0.01 & 0.442 & 1.01 & $0.98-1.04$ \\
\hline & $\mathrm{HMO}$ & -0.001 & 0.940 & 1.00 & $0.96-1.04$ \\
\hline & Other & -0.02 & 0.420 & 0.98 & $0.94-1.03$ \\
\hline \multirow[t]{12}{*}{ Comorbidities } & No congestive heart failure & - & - & - & - \\
\hline & Congestive heart failure & -0.09 & $<0.001$ & 0.91 & $0.89-0.94$ \\
\hline & No hypertension & - & - & - & - \\
\hline & Hypertension & -0.09 & $<0.001$ & 0.92 & $0.90-0.94$ \\
\hline & No diabetes mellitus & - & - & - & - \\
\hline & Diabetes mellitus & -0.11 & $<0.001$ & 0.90 & $0.87-0.92$ \\
\hline & No stroke or TIA & - & - & - & - \\
\hline & Stroke or TIA & -0.33 & $<0.001$ & 0.72 & $0.69-0.75$ \\
\hline & No anemia & - & - & - & - \\
\hline & Anemia & 0.09 & $<0.001$ & 1.10 & $1.06-1.14$ \\
\hline & No bleeding & - & - & - & - \\
\hline & Bleeding & 0.09 & $<0.001$ & 1.10 & $1.06-1.14$ \\
\hline Charlson Comorbidity Index & & 0.009 & 0.039 & 1.01 & $1.00-1.02$ \\
\hline \multirow[t]{2}{*}{ History of hospitalization or ER visits } & No & - & - & - & - \\
\hline & Yes & 0.10 & $<0.001$ & 1.11 & $1.08-1.13$ \\
\hline
\end{tabular}

tension, congestive heart failure, and diabetes than patients with discontinuation $(P<0.05)$. Significantly fewer persistent patients had anemia and history of bleeding compared with patients who discontinued warfarin $(P<0.05)$. Other significant differences among persistent patients, patients with warfarin interruption, and patients with discontinuation are displayed in Table 1.

Kaplan-Meier estimates indicated that $55.22 \%$ of patients either interrupted or discontinued warfarin within the first year of therapy. In stratified analysis, patients who were younger than 65 years were more likely to discontinue/interrupt warfarin than patients who were at least aged 65 years ( $60.7 \%$ vs. $52.7 \%$, respectively; $P<0.05$ ). Patients with bleeding were more likely to discontinue/interrupt warfarin than those without bleeding ( $58.4 \%$ vs. $54.8 \%$, respectively; $P<0.05$ ). As $\mathrm{CHADS}_{2}$ scores increased (indicating higher stroke risk), the likelihood of discontinuing/interrupting warfarin decreased $(P<0.05$; Figure 2).

\section{Predictors of Warfarin Interruption or Discontinuation}

In a multivariable analysis based on an adjusted Cox proportional hazards regression model (Wald chi-square $=858.98 ; P<0.001$; Table 2), it was found that individuals who were younger than 65 years (hazard ratio $[\mathrm{HR}]=1.22 ; 95 \%$ confidence interval $[\mathrm{CI}]=1.19-1.25)$; lived in the western United States (HR=1.07; 95\% CI $=1.03-1.11)$; had anemia $(\mathrm{HR}=1.10 ; 95 \% \mathrm{CI}=1.06$ 1.14); had bleeding episodes ( $\mathrm{HR}=1.10 ; 95 \% \mathrm{CI}=1.06-1.14)$; or were hospitalized or had emergency room visits ( $\mathrm{HR}=1.11$; 95\% CI $=1.08-1.13)$ were at significantly higher risk of warfarin discontinuation/interruption. Meanwhile, individuals who were female ( $\mathrm{HR}=0.96 ; 95 \% \mathrm{CI}=0.94-0.98)$; lived in the north central United States ( $\mathrm{HR}=0.96$; 95\% CI $=0.93-0.99)$; had congestive heart failure ( $\mathrm{HR}=0.91 ; 95 \% \mathrm{CI}=0.89-0.94)$; had hypertension ( $\mathrm{HR}=0.92 ; 95 \% \mathrm{CI}=0.90-0.94)$; had diabetes mellitus ( $\mathrm{HR}=0.90 ; 95 \% \mathrm{CI}=0.87-0.92)$; or had a history of stroke or TIA (HR $=0.72 ; 95 \% \mathrm{CI}=0.69-0.75)$ were at significantly lower risk of discontinuing/interrupting warfarin therapy. 
Discontinuation/Interruption of Warfarin Therapy in Patients with Nonvalvular Atrial Fibrillation

TABLE 3 Analyses of Clinical Factors Associated with Interruption and Discontinuation of Warfarin Therapy and in Sensitivity Analyses Based on Adjusted Cox Proportional Hazards Model

\begin{tabular}{|c|c|c|c|c|c|c|c|c|c|c|}
\hline \multirow[b]{2}{*}{ Parameter } & \multicolumn{2}{|c|}{$\begin{array}{l}\text { Patients with } \\
\text { Interruption vs. } \\
\text { Persistent Patients }\end{array}$} & \multicolumn{2}{|c|}{$\begin{array}{c}\text { Patients with } \\
\text { Discontinuation vs. } \\
\text { Persistent Patients }\end{array}$} & \multicolumn{2}{|c|}{$\begin{array}{c}\text { Prescription Gap } \\
\text { +7 Days }\end{array}$} & \multicolumn{2}{|c|}{$\begin{array}{c}\text { Prescription Gap } \\
\text { +14 Days }\end{array}$} & \multicolumn{2}{|c|}{$\begin{array}{c}\text { Prescription Gap } \\
\text { +30 Days }\end{array}$} \\
\hline & HR & $95 \%$ CI & HR & $95 \% \mathrm{CI}$ & HR & $95 \% \mathrm{CI}$ & HR & $95 \% \mathrm{CI}$ & HR & $95 \% \mathrm{CI}$ \\
\hline Age $\geq 65$ & - & - & - & - & - & - & - & - & - & - \\
\hline Age $<65$ & 0.94 & 0.89-0.99 & 1.32 & $1.28-1.36$ & 1.24 & $1.20-1.27$ & 1.26 & $1.23-1.30$ & 1.31 & $1.28-1.35$ \\
\hline Male & - & - & - & - & - & - & - & - & - & - \\
\hline Female & 1.02 & $0.97-1.06$ & 0.94 & $0.92-0.97$ & 0.96 & $0.93-0.98$ & 0.95 & $0.93-0.97$ & 0.94 & $0.92-0.97$ \\
\hline Northeast & - & - & - & - & - & - & - & - & - & - \\
\hline North central & 0.99 & $0.93-1.06$ & 0.95 & $0.92-0.99$ & 0.96 & $0.93-0.99$ & 0.96 & 0.93-0.99 & 0.95 & $0.92-0.99$ \\
\hline South & 0.99 & $0.93-1.07$ & 1.03 & $0.99-1.07$ & 1.02 & $0.98-1.05$ & 1.02 & $0.98-1.05$ & 1.02 & $0.98-1.05$ \\
\hline West & 1.09 & $1.01-1.17$ & 1.07 & $1.02-1.12$ & 1.07 & $1.03-1.11$ & 1.06 & $1.02-1.11$ & 1.05 & $1.01-1.10$ \\
\hline Other region & 0.73 & $0.48-1.13$ & 0.93 & $0.77-1.14$ & 0.95 & $0.79-1.41$ & 0.96 & $0.80-1.15$ & 0.97 & $0.80-1.17$ \\
\hline Comprehensive insurance & - & - & - & - & - & - & - & - & - & - \\
\hline $\mathrm{PPO}$ insurance & 0.96 & $0.91-1.01$ & 1.02 & 0.99-1.06 & 1.02 & $0.99-1.04$ & 1.02 & $0.94-1.05$ & 1.03 & $0.99-1.06$ \\
\hline HMO insurance & 1.07 & $0.99-1.15$ & 0.98 & $0.93-1.02$ & 1.00 & $0.96-1.04$ & 1.00 & $0.96-1.04$ & 0.99 & $0.95-1.03$ \\
\hline Other insurance & 0.89 & $0.81-0.98$ & 0.99 & $0.94-1.04$ & 0.99 & $0.95-1.04$ & 1.00 & $0.95-1.04$ & 1.01 & $0.96-1.06$ \\
\hline No history of congestive heart failure & - & - & - & - & - & - & - & - & - & - \\
\hline History of congestive heart failure & 1.04 & $0.98-1.11$ & 0.88 & $0.85-0.91$ & 0.90 & $0.88-0.93$ & 0.90 & $0.87-0.93$ & 0.89 & $0.86-0.92$ \\
\hline No history of hypertension & - & - & - & - & - & - & - & - & - & - \\
\hline History of hypertension & 0.88 & $0.84-0.93$ & 0.91 & $0.89-0.94$ & 0.92 & $0.90-0.94$ & 0.92 & $0.90-0.94$ & 0.92 & $0.90-0.94$ \\
\hline No history of diabetes mellitus & - & - & - & - & - & - & - & - & - & - \\
\hline History of diabetes mellitus & 0.99 & $0.93-1.05$ & 0.86 & $0.83-0.89$ & 0.89 & $0.86-0.92$ & 0.88 & $0.86-0.91$ & 0.87 & $0.84-0.90$ \\
\hline No history of stroke or TIA & - & - & - & - & - & - & - & - & - & - \\
\hline History of stroke or TIA & 0.82 & $0.76-0.90$ & 0.66 & $0.62-0.69$ & 0.70 & $0.67-0.73$ & 0.70 & $0.66-0.73$ & 0.69 & $0.65-0.72$ \\
\hline No history of anemia & - & - & - & - & - & - & - & - & - & - \\
\hline History of anemia & 1.04 & $0.97-1.11$ & 1.13 & $1.08-1.17$ & 1.11 & $1.07-1.14$ & 1.10 & $1.06-1.14$ & 1.12 & $1.08-1.16$ \\
\hline No history of bleeding & - & - & - & - & - & - & - & - & - & - \\
\hline History of bleeding & 1.03 & $0.96-1.11$ & 1.13 & $1.09-1.18$ & 1.11 & $1.07-1.15$ & 1.12 & $1.08-1.16$ & 1.12 & $1.08-1.17$ \\
\hline $\mathrm{CCI}$ & 1.01 & $0.99-1.03$ & 1.01 & $1.00-1.02$ & 1.01 & $1.00-1.02$ & 1.01 & $1.00-1.02$ & 1.01 & $1.00-1.02$ \\
\hline No history of hospitalization or ER & - & - & - & - & - & - & - & - & - & - \\
\hline History of hospitalization or ER & 0.99 & $0.94-1.04$ & 1.15 & $1.11-1.18$ & 1.12 & $1.09-1.14$ & 1.12 & $1.09-1.15$ & 1.13 & $1.10-1.16$ \\
\hline
\end{tabular}

When persistent patients were compared with patients who interrupted warfarin only, fewer factors were significantly associated with interruption than in the main analysis (Table 3). Individuals who lived in the West (HR $=1.09$; $95 \%$ $\mathrm{CI}=1.01-1.17)$ were at significantly higher risk of warfarin interruption. Individuals who were younger than aged 65 years ( $\mathrm{HR}=0.94 ; 95 \% \mathrm{CI}=0.89-0.99$ ); had insurance other than PPO or HMO (HR=0.89; 95\% CI=0.81-0.98); had hypertension $(\mathrm{HR}=0.88 ; 95 \% \mathrm{CI}=0.84-0.93)$; or had a history of stroke or TIA (HR $=0.82 ; 95 \% \mathrm{CI}=0.76-0.90)$ were at significantly lower risk of warfarin interruption. When persistent patients were compared with patients who discontinuted warfarin only, the significant factors associated with warfarin discontinuation were consistent with the main analysis. When additional analyses were conducted to determine the factors associated with warfarin discontinuation/interruption by varying prescription gaps $(7,14$, and 30 days), the significant factors associated with discontinuation/interruption were similar to the main analysis when the prescription gaps were increased (Table 3) and decreased (results not shown).

\section{Discussion}

In this retrospective observational study involving a large sample of NVAF patients, we examined the rates and predictors of warfarin interruption and discontinuation. More than half of the study participants interrupted or discontinued warfarin therapy during the first year of use: $11.77 \%$ of patients interrupted warfarin therapy without discontinuation, and $43.45 \%$ of patients discontinued warfarin therapy with or without interruption, a total of $55.22 \%$. Less than half of the study participants, $44.79 \%$, were persistent in their warfarin use. It is noteworthy that this study differentiated between discontinuation and interruption and found that a far greater percentage of patients discontinued warfarin therapy rather than interrupting therapy for a brief period of time. 
The combined rates of warfarin discontinuation/interruption estimated in this study are generally consistent with previous studies in the United States. For example, Song et al. (2012) found that $42.6 \%$ of AF patients discontinued warfarin (with a gap of at least 90 days between warfarin prescriptions) within the first year of use..$^{24}$ Deitelzweig et al. (2013) found that $51.4 \%$ of NVAF patients discontinued warfarin therapy (with a gap over 60 days between warfarin prescriptions) at least once during follow-up (the mean duration of follow-up was 668 days). ${ }^{36}$ However, in a study of long-term care patients, Patel et al. found a 1-year discontinuation rate (with a gap over 37 days between warfarin prescriptions) of $65 \% .{ }^{25}$ Likewise, the interruption rate in this study was much lower than the rate suggested by the Rauns $\varnothing$ et al. study (2012) using the Danish National Patient Registry. ${ }^{26}$ In that study, $72 \%$ of patients had at least 1 interruption of warfarin therapy (any gap between warfarin prescriptions). ${ }^{26}$ Variations in study population, study design, and statistical methods may help to explain these differences.

The high combined rate of warfarin discontinuation and interruption among NVAF patients is a cause of concern. Raunsø et al. found that warfarin interruption was associated with increased risk of thromboembolic events and death among AF patients. ${ }^{26}$ Likewise, Deitelzweig et al. found increased stroke risk during periods of warfarin discontinuation among patients with NVAF. ${ }^{36}$ This study suggested that history of stroke/TIA served as a protective factor against discontinuation/interruption. Similarly, in the Kaplan-Meier analysis, patients with higher $\mathrm{CHADS}_{2}$ scores (an indicator of increased stroke risk) had longer time to first incident of warfarin discontinuation/interruption compared with patients who had lower scores. Recall that the calculation of $\mathrm{CHADS}_{2}$ scores includes history of stroke or TIA. Patients with a history of stroke or TIA may, as a result of these experiences, have greater awareness or knowledge of the health risks associated with $\mathrm{AF}$ and the need to adhere to medication regimens to improve health outcomes. Consequently, they may be more likely to remain persistent on warfarin therapy. Physicians also may be less likely to discontinue/interrupt warfarin therapy for patients with a history of stroke or TIA. Given the high prevalence of warfarin discontinuation/interruption and its possible negative outcome on patient health, health care providers should take a more active role in addressing this issue. They should better understand the causes for warfarin discontinuation/interruption, inform patients about the negative consequences of warfarin discontinuation/interruption, and help patients to resolve barriers to warfarin persistence. Health care providers may also consider prescribing alternative anticoagulants, such as newer anticoagulants with more favorable risk-benefit profiles than warfarin and without a need for INR monitoring. ${ }^{37}$

In the main analysis, the finding of the current study that bleeding and hospitalizations/emergency room visits prior to warfarin initiation are associated with increased risk of warfarin discontinuation/interruption is consistent across prior studies. ${ }^{18,20}$ Bleeding risk may be higher among patients with prior bleeding, which may be a reason for this pattern. Prior hospitalizations and emergency room visits may be proxy measures for worse health status, and they may serve the same purposes as prior stroke or TIA or the Charlson Comorbidity Index. However, there is a lack of consistency between this study's findings and those of previous studies regarding some other patient factors and their association with warfarin use. . $^{184,25}$ Consistent with the findings from this study, Song et al. found that older patients had a lower risk of discontinuation, ${ }^{24}$ and Suh et al. found that being female was associated with reduced likelihood of discontinuation. ${ }^{18}$ However, in the same Suh et al. study, older age (greater than 85 years) was associated with increased risk of discontinuation. ${ }^{18}$ Patel et al. also found that older age (65 to 74 years) was related to warfarin discontinuation and that being female was associated with warfarin discontinuation. ${ }^{25}$ Variations in study population, study design, and data analysis methods may again help to explain these differences. Additional research is needed to build a more comprehensive understanding of the relationships among demographic, clinical, and health care-related factors and warfarin persistency patterns, which will help clinicians to determine strategies to improve patient persistence with anticoagulation.

In our subanalyses, when the persistent group was compared with the interruption group only and the discontinuation group only, a few interesting findings emerged. Compared with the main analysis that involved the combined discontinuation/interruption group and noted several factors that increased risk of discontinuation/interruption, the persistent group versus interruption group only analysis found that the only factor that increased risk of interruption was living in the western United States. Moreover, age less than 65 years, a risk factor in the main analysis, seemed to act as a protective factor in the interruption group only analysis. In contrast, factors associated with warfarin discontinuation were consistent with the main analysis. These results suggest that it is useful to distinguish between warfarin interruption and discontinuation in such assessments, since risk and protective factors may vary. In future studies, distinction between interruption and discontinuation and determination of different causes for interruption and discontinuation may reveal more extensive information regarding warfarin persistency patterns and may assist health care providers in developing interventions to improve consistent use of warfarin. Additionally, future research should also further the current literature by determining the clinical and economic implications of warfarin interruption and discontinuation.

\section{Limitations}

There are several limitations to this study. First, although we can link some population subgroups to discontinuation/interruption and thus find potential predictors for warfarin discontinuation/interruption, it is impossible to know the reasons for 
discontinuation/interruption due to the observational nature of the study. Second, there is a possibility that the method of identifying the discontinuation and interruption periods may underestimate the length of disruptions/interruptions because discontinuations/interruptions were identified when there was an estimated zero tablet remaining in the patients' prescriptions. In reality, patients may interrupt therapy while still possessing medications. Third, this study was based on administrative databases that did not include some clinical parameters related to outcome events, such as body mass index, smoking status, left ventricular ejection fraction, lipid measures, and INR values. Fourth, we did not have inpatient records of medication utilization for patients who were hospitalized during the study period. Therefore, we were unable to determine what medications the patients were given in the hospital. Additionally, we did not consider the possible effects of concomitant medications on warfarin persistence or discontinuation/interruption. Despite these limitations, the findings of the current study made significant contribution to the existing literature by elaborating on the rate of warfarin discontinuation/ interruption among NVAF patients and identifying predictors of discontinuation/interruption using a national database when studying warfarin persistency patterns. The method of identifying discontinuation and interruption for this study is generally reliable because study findings are consistent with the previous studies. Additionally, the inclusion of INR monitoring also accounted for anticoagulation monitoring services.

\section{Conclusions}

In this administrative database study, rates of warfarin use, as well as factors related to warfarin interruption, discontinuation, and persistence were examined in U.S. patients with NVAF. More than 50\% of NVAF patients discontinued or interrupted warfarin use during the 1-year follow-up, and patients who were aged less than 65 years and had a history of anemia, bleeding, or hospitalization/emergency room visits were at higher risk of warfarin discontinuation/interruption. Considering the prevalence of warfarin discontinuation/interruption and the possible consequences for patient health, health care providers should take a more active role in understanding the reasons behind patient discontinuation/interruption, counsel patients on the risks and costs of discontinuation/ interruption, and help patients identify and resolve barriers to consistent use of warfarin. Health care providers may also want to consider prescribing alternatives anticoagulants, such as newer anticoagulants with more favorable risk-benefit profiles and without a need to monitor INR.

\section{Authors}

CHRISTINA A. SPIVEY, PhD, is Assistant Professor; YANRU QIAO, MS, is Data Analyst; ROBERT B. PARKER, PharmD, is Professor; ANWESA CHAKRABARTI, is PharmD Candidate, Class of 2015, and JUNLING WANG, PhD, is Associate Professor, University of Tennessee College of Pharmacy, Memphis. XIANCHEN LIU, MD, PhD, is Director, Global Health Economics \& Outcomes Research, Pfizer, Inc., New York, New York, and Adjunct Professor, University of Tennessee College of Pharmacy, Memphis. JACK MARDEKIAN, $\mathrm{PhD}$, is Senior Director, Statistics; ABIGAIL B. CLAFLIN, MPH, is Research Associate, Global Health Economics \& Outcomes Research; and YOUNOS ABDULSATTAR, PharmD, BCPS, is Director, Global Medical Affairs, Pfizer, Inc., New York, New York. HEMANT PHATAK, PhD, is Director, and SUMESH KACHROO, PhD, is Associate Director, Global Health Economics \& Outcomes Research, Bristol-Myers Squibb, Princeton, New Jersey.

AUTHOR CORRESPONDENCE: Junling Wang, PhD, Associate Professor, Dept. of Clinical Pharmacy, University of Tennessee College of Pharmacy, 881 Madison Ave., Ste. 221, Memphis, TN 38163. Tel.: 901.448.3601; Fax: 901.448.1221;

E-mail: jwang26@uthsc.edu.

\section{DISCLOSURES}

This project was funded by Pfizer and Bristol-Myers Squibb. Liu, Mardekian, Claflin, and Abdulsattar are employed by Pfizer. Phatak and Kachroo are employed by Bristol-Myers Squibb.

Study concept and design were primarily contributed by Liu, Wang, and Phatak, along with the rest of the authors. Qiao, Mardekian, and Liu were primarily responsible for data collection, assisted by the rest of the authors. Data interpretation was performed primarily by Phatak, Claflin, and Abdulsattar, with assistance from the rest of the authors. The manuscript was written primarily by Spivey, Chakrabarti, and Wang, with assistance from the rest of the authors, and revised by Parker, Kachoo, Wang, and Spivey, with assistance from the rest of the authors.

\section{REFERENCES}

1. Fuster V, Rydén LE, Cannom DS, et al. ACC/AHA/ESC 2006 guidelines for the management of patients with atrial fibrillation-executive summary: a report of the American College of Cardiology/American Heart Association Task Force on Practice Guidelines and the European Society of Cardiology Committee for Practice Guidelines (Writing Committee to Revise the 2001 Guidelines for the Management of Patients with Atrial Fibrillation). J Am Coll Cardiol. 2006;48(4):854-906.

2. Wann LS, Curtis AB, January CT, et al. 2011 ACCF/AHA/HRS focused update on the management of patients with atrial fibrillation (updating the 2006 guideline): a report of the American College of Cardiology Foundation/ American Heart Association Task Force on Practice Guidelines. J Am Coll Cardiol. 2011;57(2):223-42

3. Camm AJ, Kirchhof P, Lip GY, et al. Guidelines for the management of atrial fibrillation: the Task Force for the Management of Atrial Fibrillation of the European Society of Cardiology (ESC). Eur Heart J. 2010;31(19):2369-429. 
4. Go AS, Hylek EM, Phillips KA, et al. Prevalence of diagnosed atrial fibrillation in adults. National implications for rhythm management and stroke prevention: the AnTicoagulation and Risk Factors in Atrial Fibrillation (ATRIA) study. JAMA. 2001;285(18):2370-75.

5. Colilla S, Crow A, Petkun W, Singer DE, Simon T, Liu X. Estimates of current and future incidence and prevalence of atrial fibrillation in the U.S. adult population. Am J Cardiol. 2013;112(8):1142-47.

6. National Institutes of Health. What is atrial fibrillation? September 18 , 2014. Available at: http://www.nhlbi.nih.gov/health/health-topics/topics/af/. Accessed May 15, 2015.

7. Wolf PA, Abbott RD, Kannel WB. Atrial fibrillation as an independent risk factor for stroke: the Framingham Study. Stroke. 1991;22(8):983-88.

8. You JJ, Singer DE, Howard PA, et al. Antithrombotic therapy for atrial fibrillation: Antithrombotic Therapy and Prevention of Thrombosis, 9th ed.: American College of Chest Physicians Evidence-Based Clinical Practice Guidelines. Chest. 2012;141(2 Suppl):e531S-e75S.

9. Rietbrock S, Plumb JM, Gallagher AM, van Staa TP. How effective are dose-adjusted warfarin and aspirin for the prevention of stroke in patients with chronic atrial fibrillation? An analysis of the UK General Practice Research Database. Thromb Haemost. 2009;101(3):527-34.

10. Fang MC, Go AS, Chang Y, et al. Thirty-day mortality after ischemic stroke and intracranial hemorrhage in patients with atrial fibrillation on and off anticoagulants. Stroke. 2012;43(7):1795-99.

11. Darkow T, Vanderplas AM, Lew KH, Kim J, Hauch O. Treatment patterns and real-world effectiveness of warfarin in nonvalvular atrial fibrillation within a managed care system. Curr Med Res Opin. 2005;21(10):1583-94.

12. Ghate SR, Biskupiak J, Ye X, Kwong WJ, Brixner DI. All-cause and bleeding-related health care costs in warfarin-treated patients with atrial fibrillation. J Manag Care Pharm. 2011;17(9):672-84. Available at: http:// www.amcp.org/JMCP/2011/November__December/13680/1033.html.

13. Peterson P, Boysen G, Godtfredsen J, Andersen ED, Andersen B. Placebo-controlled, randomised trial of warfarin and aspirin for prevention of thromboembolic complications in chronic atrial fibrillation. The Copenhagen AFASAK study. Lancet. 1989;1(8631):175-79.

14. Stroke Prevention in Atrial Fibrillation Study Group Investigators. Preliminary report of the Stroke Prevention in Atrial Fibrillation Study. N Engl J Med. 1990;322(12):863-68.

15. The Boston Area Anticoagulation Trial for Atrial Fibrillation Investigators. The effect of low-dose warfarin on the risk of stroke in patients with nonrheumatic atrial fibrillation. New Engl J Med. 1990;323(22):1505-11.

16. Ezekowitz MD, Bridgers SL, James KE, et al. Warfarin in the prevention of stroke associated with nonrheumatic atrial fibrillation. New Engl J Med. 1992;327(20):1406-12.

17. Mercaldi CJ, Ciarametaro M, Hahn B, et al. Cost efficiency of anticoagulation with warfarin to prevent stroke in Medicare beneficiaries with nonvalvular atrial fibrillation. Stroke. 2011;42(1):112-18.

18. Suh DC, Choi JC, Schein J, Kim S, Nelson WW. Factors associated with warfarin discontinuation, including bleeding patterns, in atrial fibrillation patients. Curr Med Res Opin. 2013;29(7):761-71.
19. Kim MM, Metlay J, Cohen A, et al. Hospitalization costs associated with warfarin-related bleeding events among older community-dwelling adults. Pharmacoepidemiol Drug Saf. 2010;19(7):731-36.

20. Fang MC, Go AS, Chang Y, et al. Warfarin discontinuation after starting warfarin for atrial fibrillation. Circ Cardiovasc Qual Outcomes. 2010;3(6):624-31.

21. Ewen E, Zhang Z, Simon TA, Kolm P, Liu X, Weintraub WS. Patterns of warfarin use and subsequent outcomes in atrial fibrillation in primary care practices. Vasc Health Risk Manag. 2012;8:587-98.

22. Reynolds MR, Shah J, Essebag V, et al. Patterns and predictors of warfarin use in patients with new-onset atrial fibrillation from the FRACTAL Registry. Am J Cardiol. 2006;97(4):538-43.

23. Gallagher AM, Rietbrock S, Plumb J, van Staa TP. Initiation and persistence of warfarin or aspirin in patients with chronic atrial fibrillation in general practice: do the appropriate patients receive stroke prophylaxis. J Thromb Haemost. 2008;6(9):1500-06.

24. Song X, Sander SD, Varker H, Amin A. Patterns and predictors of use of warfarin and other common long-term medications in patients with atrial fibrillation. Am J Cardiovasc Drugs. 2012;12(4):245-53.

25. Patel AA, Reardon G, Nelson WW, Philpot T, Neidecker MV. Persistence of warfarin therapy for residents in long-term care who have atrial fibrillation. Clin Ther. 2013;35(11):1794-804

26. Raunsø J, Selmer C, Olesen JB, et al. Increased short-term risk of thrombo-embolism or death after interruption of warfarin treatment in patients with atrial fibrillation. Eur Heart J. 2012;33(15):1886-92.

27. Garcia DA, Regan S, Henault LE, et al. Risk of thromboembolism with short-term interruption of warfarin therapy. Arch Intern Med. 2008;168(1):63-69.

28. Sherman DG, Kim SG, Boop BS, et al. Occurrence and characteristics of stroke events in the Atrial Fibrillation Follow-up Investigation of Sinus Rhythm Management (AFFIRM) study. Arch Intern Med. 2005;165(10):1185-91.

29. Casciano JP, Dotiwala ZJ, Martin BC, Kwong WJ. The costs of warfarin underuse and nonadherence in patients with atrial fibrillation: a commercial insurer perspective. J Manag Care Pharm. 2013;19(4):302-16. Available at: http://www.amcp.org/JMCP/2013/May/16520/1033.html.

30. Wang J, Liu X, Mullins CD. Treatment adherence and persistence with duloxetine, venlafaxine XR, and escitalopram among patients with major depressive disorder and chronic pain-related diseases. Curr Med Res Opin. 2011;27(7):1303-13.

31. U.S. Food and Drug Administration. FDA drug safety communication: update on the risk for serious bleeding events with anticoagulant Pradaxa (dabigatran). August 14, 2014. Available at: http://www.fda.gov/drugs/drugsafety/ucm326580.htm. Accessed May 15, 2015.

32. Truven Health Analytics. RED BOOK. Available at: http://www.redbook. com/redbook/. Accessed May 15, 2015.

33. Go AS, Hylek EM, Chang Y, et al. Anticoagulation therapy for stroke prevention in atrial fibrillation: how well do randomized trials translate into clinical practice? JAMA. 2003;290(20):2685-92. Available at: http://jama.jamanetwork.com/article.aspx?articleid=197710. Accessed May $15,2015$. 
34. Svendsen JH, Nielsen JC, Darkner S, et al. $\mathrm{CHADS}_{2}$ and $\mathrm{CHA}_{2} \mathrm{DS}_{2}-\mathrm{VASc}$ score to assess risk of stroke and death in patients paced for sick sinus syndrome. Heart. 2013;99(12):843-48. Available at: http://www.ncbi.nlm.nih. gov/pmc/articles/PMC3664372/. Accessed May 15, 2015.

35. Charlson ME, Pompei P, Ales KL, MacKenzie CR. A new method of classifying prognostic comorbidity in longitudinal study: development and validation. J Chronic Dis. 1987;40(5):373-83.
36. Deitelzweig SB, Buysman E, Pinsky B, et al. Warfarin use and stroke risk among patients with nonvalvular atrial fibrillation in a large managed care population. Clin Ther. 2013;35(8):1201-10.

37. Ruff CT, Giugliano RP, Branuwald E, et al. Comparison of the efficacy and safety of new oral anticoagulants with warfarin in patients with atrial fibrillation: a meta-analysis of randomized trials. Lancet. 2014;383(9921):955-62. 